\title{
ITALIAN GRADUATION DAY: A NEW MODEL OF RITUAL
}

\section{GIORGIA RICONDA}

Department of Sociology and Social Research, University of Milan Bicocca,

Piazza dell'Ateneo Nuovo, 1, 20126 Milano MI, Italy

Email address: g.riconda@campus.unimib.it

https://orcid.org/0000-0003-1209-1213

\begin{abstract}
Aims. The research aims to reconstruct the phases of the new ritual of graduation in Italy to fully understand if there is a variety of social forms and conventions (linked to symbolic aspects) to be satisfied and if there are elements of ambiguity.

Methods. Using ethnographic technique, I chose to develop, on the one hand, a thick description of the ritual that highlights the "stratified hierarchy of significant structures" (Geertz, 1998) while, on the other, I tried to develop a comparative methodology that takes into account both temporal and spatial levels of some of the different graduation ritual models that exist and have existed.

Results. The analysis shows that there is a lack of consistency between the new degree model and the new graduation ceremony model. Furthermore, on the one hand, the liminal theatricality of the rite satisfies the demands of collective catharsis; on the other hand, there are some ambivalences and there is a lack of consistency between the conventions (and their symbolisms) in the ceremony and the university experiences that students could have in Italy.

Lastly, the moral entrepreneurs paid too little attention to the original meanings of the model of celebration from which it draws and its criticality.

Conclusions. Rituals in the educational field are very important socio-cultural forms of production of meanings whose modification could be more satisfactory if there was a greater reflection on the original educational models and if, in this reflection, there was involved a large number of subjects belonging to different groups.

Key words: culture, ethnography, ritual, rite of passage, genre, education, education ritual, graduation, Italy.
\end{abstract}

\section{INTRODUCTION}

$\mathrm{M}$ agolda (2003), an American professor who has carried out several researches on the theme of educational processes, offering support to the arguments of Quantz (1999), McLaren (1999) and Burnett (1969), said that the rituals taking place in educational contexts are rarely examined. However, they are important sources for revealing social and cultural conditions, they reveal a lot about the organizers and the participants of the ritual, and they are political 
acts that communicate expectations and norms of behavior. Among these, one of the most significant rites of passage is certainly the Graduation Ceremony, which, however, takes on different forms and methods both at temporal and spatial levels. In July 2011, on the Grande Guida Università of the Italian newspaper La Repubblica - an annual guidebook to Italian universities and their degree programs for those wishing to enroll in university - it was highlighted that, in many Italian universities, the discussion of the bachelor's thesis had been abolished: "Far off are the times when entire families emigrated from the provinces to reach their graduating children in the university metropolis where, in five minutes of dissertation, they came out of the lecture hall more or less happy and with the fateful piece of paper in their hands. In 2011 the thesis is (almost) not discussed anymore, but the degree is the same. The three-year degree can be achieved without facing the burdens and honors of academic dissertations" (Bernabei, 2011). So the abolition of the degree discussion has been placed at the center of the media debate from the beginning. Specifically, when Bernabei speaks about "burdens and honors in addressing academic dissertations," he correctly summarizes both of the reactions that public opinion expected of the students and the actual response of the students themselves: on the one hand, the expectations of many people that the students would breathe a sigh of relief in avoiding the discussion of the final paper and, on the other hand, the reaction of a significant part of the students to challenge the abolition of the discussion, arguing that the graduation session is one of the few moments of recognition of the creative study work done in the three-year course of study (Roesel, 2006).

Consequently, the resulting debate has led university rectors to explain the reasons for the change: from the structural difficulties that lead to the need to reduce the number of graduation sessions (and the crowds involved in graduation ceremonies) to the wish to speed up and facilitate the transition to master's degrees; from the observation of a diminished quality of the final paper to the belief that "[Sinigaglia, University of Milan] the methods of execution of public discussion belong to a cultural heritage now out of date and then to be changed" (Roesel, 2006); from the conviction that, already in the first cycle, there are opportunities for students to demonstrate their creativity to the wish, finally, to adapt the local university model to the international one. So, in what context are these considerations generated? As Barone (2012) argues, the paradigm of mass education is the idea that scholastic expansion is a form of social progress that responds to the growing need for skilled labor in industrialized countries with the aim of combating social inequalities and the need to guarantee equal opportunities for active citizenship to everyone. In the fifties and sixties the expansion of education was really a lever of greater social openness and material well-being (Ballarino \& Schadee, 2008) but, in Italy, the "open door policy" - the admission of high school graduates to any university course without barriers - was also adopted without really reflecting on the aims of the university and its relationship with the labor market (Moscati, 2010). Only with the advent of the first Ministry of University and Scientific Research (1989), has 
the ministry tried to connect the Italian university system to the processes that were already taking place in other European countries.

Subsequently, the opportunity was identified with the so-called "Bologna Process" launched in 1998 (Moscati, 2010): "a collective European process that aims to introduce a system divided into three cycles (Bachelor / Master / Doctorate) strengthening quality assurance and facilitating the recognition of qualifications and periods of study." In Italy, the Bologna Process had its most decisive effects in the $3+2$ reform governed by Ministerial Decree 509 of 3 November 1999 (and then reaffirmed by Ministerial Decree No. 270 of 22 October 2004), from the application of which different levels of university education were born: the three-year degree (Bachelor), called "Laurea (L)," and the "Laurea Magistrale (LM)," which provides for another two years of specialization (Master) and replaced the previous four-year and five-year degrees.

In this new scenario, the Bachelor's degree has the objective of ensuring a student an adequate mastery of general scientific methods and content, even if it is oriented towards the acquisition of specific professional knowledge (Quadro italiano dei Titoli Universitari, 2010) while the Master's degree aims to provide a student with an advanced level of training for the performation of highly qualified activities in specific areas (Quadro italiano dei Titoli Universitari, 2010). As Barone (2012) points out, the problems that the reform has posed are many:

a) the hybrid identity of the Bachelors, which should at the same time professionalize and provide the basis for the Master's;

b) the sharp increase in the number of graduates, stimulated by the reform of $3+2$ (although, according to the 2018 ISTAT data, Italy - by number of graduates - is the penultimate among the European Union countries);

c) with reference to what the job market could offer to new graduates, several degree programs were seriously inflated compared to others already before the university reform and the reform did not solve the problem;

d) the danger that those who hold the master's degree will take away the jobs from those with the Bachelor's degrees.

In fact, if the uncontrolled expansion of bachelor enrolled students pushes many students to continue studying to obtain a master's degree, even just to secure a competitive advantage over those who have obtained bachelor's degrees, the risk of a devaluation of the first cycle degree increases. So, starting from an ethnography of the case of the new graduation ritual of the $\mathrm{Ca}$ 'Foscari University of Venice in comparison with the already canonized variants of the genre, the research question I will try to answer is: Why is the new graduation ceremony being challenged? Are there elements of ambiguity and dissonance? In the "graduation ritual," should there be a variety of social forms and conventions (linked to symbolic aspects) to be satisfied? In addition, is it a more anachronistic university system that makes the students celebrate this passage in an individual ceremony when there is the awareness that the obtaining of the Bachelor's degree is now a mass phenomenon or is it a more anachronistic university that makes one celebrate the passage in a collective 
ceremony when there is the awareness of depriving the student of one of the few moments of individual celebration in which he or she can really believe in the validity of that degree of study provided by the university?

\section{THE "AMERICAN" REVOLUTION OF THE CA 'FOSCARI UNIVERSITY OF VENICE}

In February 2011, Carlo Carraro, rector of the Ca 'Foscari University of Venice, approved a new statute that reforms the methods for obtaining the Bachelor's degree of the University of Venice with the abolition of the discussion of the final paper (the so-called "prova finale"). The University of Venice is one of the first Italian universities to have changed the system and Carraro states that it is expected to set up a "graduation day" to deliver the degrees. Initially, the university does not explain the new ways in which the "graduation day" will be carried out but, ironically, some journalist was able to predict the future and writes: "Last thing we need is the classic hats to be thrown in the air ... and the Venetian lagoon might seem like an American university colony" (Ferro, 2011). In the meantime, many students publicly said they are against the Rector's choice and some joined a Facebook group to make their voices heard: "it is unjust that after so many sacrifices ... after 36 exams ... there is no discussion of the thesis! Not even a proclamation! In the hope of change ... sign up!". At that point the Rector, after having specified that the ceremony will take place in the prestigious setting of Piazza San Marco, responded to the criticisms that began to grow in different media channels, justifying the choice and saying: "This year even the Sorbonne, temple of the French tradition, certainly not anglophile, adopts the same procedure. And even China does it. We could therefore say that we refer to the example of the Sorbonne. The ceremony in Saint Mark's Square will serve to make an important day memorable and to give further prestige to an already prestigious university such as Ca 'Foscari." In addition, he said: "For half of the students there had not been discussion for several years, and for several years they have appreciated the change that speeds up the course of study allowing them to then enroll in the master's degrees in the right time. A few students of the Faculty of Arts and Languages have protested that it is normal when any change is introduced! The Bachelor's degree is not devalued at all, because its value does not depend on the modality of achievement, but on the content learned and the prestige of the institution in which it is studied" (Controcampus, 2012). On 1st July 2011 the first "Venetian graduation day" took place and the journalists wrote that, in front of an audience of 2500 people, 500 students tossed the "cap," typical headgear of the day of the American graduation, in one of the most evocative and visited places of the country, Saint Mark's Square (Ferro 2011). In this regard, it is interesting to note that, despite the university continuing to call it "giorno di laurea" through its communication channels, the media - perhaps perceiving the tendency to approach the English-speaking world - have already called it 
"graduation day." Over the following years, with small variations, different ceremonies followed one another and on April 21st 2017, the 18th day of the University Ca 'Foscari took place.

\section{THEORETICAL FRAME}

\section{The degree as a rite of passage}

Addressing the recent graduates at a public meeting, Guido Gili, professor of sociology at the University of Molise, said: "In the face of the many graduates of today in different disciplines and fields of knowledge, I asked myself what word to base my intervention on today and I said that this word could be "passage." Yes, because today we are celebrating with a special ceremonial underlining what anthropologists and sociologists call a rite of passage. Supporting the degree exam, obtaining a degree, is a rite of passage. A moment that marks a passage of status, of condition. You know that in the traditional societies there were initiation rites that marked the entry of the boys into the adult world, with a consequent change of social status. They literally became another person. These rituals also generally provided evidence of courage and pain control and often involved wounds and real risks for personal safety. Here no cruel and dangerous performances are required, but even in these cases courage, stone coolness and self-control are required, for example in the capacity to manage emotional tension and to be able to defend the thesis in front of the commission. And, in any case, it is an effective passage of status, a bit like what happens in the investiture ceremonies. When the president of the commission says: "with the powers conferred on me by the law and by the Magnificent Rector of the University of Molise, I proclaimed doctors in..., at that moment and for the 'strength' of those words, of that formula (as the sociolinguists say), your social status changes because from that moment you can rely on that title of doctor (doctor, in this case, means: a graduate of the Bachelor's degree), for example in an open competition". Therefore, regardless of the form they take, the graduation ceremonies are rites of passage as described by Van Gennep (1981): "rituals that accompany every modification of place, status, social position and age." In his vision, every passage implies the overcoming of a threshold which, in order to be fully realized, requires a rite. This brings out a relevant fact: all these worlds in which we transit exist not by nature but because they are socially and culturally manufactured (Navarini, 2003).

And, what form has the rite of passage taken? Van Gennep distinguishes three sequential stages of rites of passage: separation (séparation), margin (limen) and incorporation (aggrégation). The first phase includes a symbolic behavior which means the separation of the individual or group from a point previously established in the social structure, from a set of cultural conditions. During the following liminal period, the characteristics of the subject in the rite (the 'passenger') are ambiguous; he or she passes through a cultural situation that has few attributes (or none) of either the past or the coming situation: he 
or she feels a sense of separation from everyday life but also a feeling of sharing towards other subjects who are in the same condition ("communitas"). In the third phase (reassembling or reincorporation) the passage is completed. The subject of the ritual, individual or collective, is again in a relatively stable situation, in which it has clearly defined rights and duties and society expects him or her to behave according to certain traditional norms and ethical criteria that place him or her in a social position that it is part of a system of positions (Turner, 2001). The anthropologist Victor Turner (2001) has analyzed the rite of passage (as formulated by Van Gennep) with particular reference to the necessary ambiguity of the attributes of liminality. In fact, liminal beings are neither on one side nor the other; they are in an intermediate space (betwixt and between) between the positions assigned and distributed by law, custom, conventions and ceremonial. As such, the ambiguity and indeterminacy of their attributes find expression in a rich variety of symbols in many societies that ritualize cultural and social transitions: they are often represented as those who have nothing or do not have anything that can distinguish them from other neophytes, and usually their behavior is humble and passive. The aim is to reduce or level them to a uniform condition, to reshape them from the beginning and equip them with new skills to enable them to cope with their new situation in life (Turner, 2001). Furthermore, Turner coined the term liminoid to refer to experiences that have characteristics of liminal experiences, but are not mandatory and do not imply the resolution of a personal crisis. According to him, if the liminal is part of society, an aspect of the social or religious rite, the liminoid is a break from the society: "Liminal phenomena are usually collective, linked to seasonal, biological or sociostructural rhythms or to crises in social processes, whether they are produced by internal settlements, by adaptations to external situations or by ways of remedying negative events; in short they appear in what can be defined as 'natural fractures,' natural interruptions of the flow of natural and social processes. Thus, they are imposed by a socio-cultural necessity, yet they contain the freedom and potential for the formation of new ideas, symbols, models and beliefs. Liminoid phenomena can be collective phenomena, but their most typical character is to be individual productions, even if their effect is often collective or mass. Their creation is not cyclical, but continues, although it takes place in places and times separated by work contexts and destined for leisure activities. Liminal phenomena tend to be similar to the 'collective representations' of Durkheim, that is to say, symbols that have the same intellectual and emotional meaning for all members of the group. Liminoid phenomena tend to be more idiosyncratic, more original, and to be produced by specialized individuals and to contend for general recognition within particular groups, such as 'schools' and circles. The liminoid resembles a commodity (you choose and you pay) more than the liminal, which arouses feelings of loyalty and is linked to belonging, or to the aspiration of belonging of the individual to some group endowed with a strong internal cohesion." Starting from these perspectives and comparatively studying the graduation ceremony, the questions I will try to answer are: How 
are the graduation rituals compared to the sequential stages highlighted by Van Gennep and Turner? Do they have affinities with liminoid phenomena?

\section{The graduation ritual as a genre developed by moral entrepreneurs}

What is clear is that if it is possible to do a comparative research, it is because we can use the concept of genre which, as Griswold says, while not admitting any Aristotelian fixity, is consolidated through a real process of "canonization" (Tota, 2003): "Making genre distinctions involves selecting, seeing the similarities in different literary objects, abstracting the common elements from a tangle of particular variations"(Griswold, 2009). Thus, considering that the genres are temporary and express the changing nature of their creators, the public and the contexts, we can refer to and paraphrase Wagner-Pacifici and Schwart, saying: When is a degree no longer a degree? When is a graduation ritual no longer a graduation ritual? Is there an essence of identifiable graduation rituality? Does this essence translate the different concepts of the graduation ceremony into the new graduation ritual? The answer is clearly in expectation (associated with the graduation ritual project) that is met by a variety of social forms and conventions that translate metaphorically into particular symbolic aspects. However, before emphasizing similarities and differences of the object in question with other cultural objects (Griswold, 2009), it is important to remember that if in Italy there is currently a new degree ritual that to a certain extent deviates from (or is a variant of) that canonized many years ago, this means there are some subjects who have committed themselves so that the ritual could be reformed. These subjects can be compared to those "moral entrepreneurs" that Becker (1991) defines as follows: "The prototype is the moral crusader of reforms. He is interested in the content of the laws. The existing ones do not satisfy him because there is some form of evil that disturbs him deeply. He believes that the world will not be right at all until laws are made to correct it. He works with absolute ethics." In the case of the Venetian ritual, moral entrepreneurs are largely identified in the university staff (mainly the rector and the teaching body) and, to a lesser extent, in the ministers of education. If, in fact, it is true that (as specified by Claudio Giunta) the decision to abolish the discussion of the three-year thesis does not depend on the Ministry but on the individual universities (ministerial decree no. 270 of 22nd October 2004 establishes that it is the didactic council of the various Bachelors that determines "the characteristics of the final examination for the attainment of the qualification"), it is also true that "the change in the role of the state towards universities, which has changed from being a controller to an evaluator, has had a very strong impact on the professional status of academic staff: on the one hand, it introduced and generalized forms of control, of the product, but also of the processes that lead to the product. It has also entered the professional life of teachers/researchers by demonstrating, with the request for evaluation, a lack of confidence in the category. As a protector-advisor (who willingly delegated important roles of responsibility in the functioning of the system and of the single university institutions), the state has thus become the judge with prize-punishment powers. And this change was combined with a condition of 
greater autonomy of initiative of the single universities that were thus left free (but alone) in structuring their political choices, but with the scarecrow of the expost evaluation" (Moscati, 2010).

\section{Research methods and techniques}

Starting from the premise that ethnographic research does not claim to be objective or exhaustive, but to illustrate in an original way aspects, worlds or dimensions of social life from "points of view" inevitably partial (Dal lago e De biasi 2002), I chose to develop, on the one hand, a detailed description of the ritual that highlights the "stratified hierarchy of significant structures" (Geertz, 1998), while on the other, I tried to develop a comparative methodology that takes into account both temporal and spatial of some of the different graduation ritual models that exist and have existed. The type of deep description I have chosen to adopt - configuring as the recording and description of meanings that do not derive from the structural determinants or functions of the system, but which are stratified by the densities in which local actions and interactions take place and in the way in which these are interpreted by the members within a flow of "social commentaries" (Navarini, 2003) - also takes into consideration the interpretations of the persons involved in the ritual, who have been interviewed informally, and incorporate them to those of the researcher. Furthermore, this dense observation - in addition to taking into account staging, script and performance (Magolda, 2003) - concerns not only the aspects within sight and other perceptual senses, but also uses all the filters and means that a society of communication can offer (Dal Lago, \& De Biasi, 2002) as newspaper articles, interviews, videos etc.

\section{Graduation: variants of a ritual genre}

One of the most interesting aspects of the new Ca 'Foscari University of Venice ritual is the way in which it was designed compared to two already established genre variations: the Italian tradition of the graduation session with discussion of the written work and the American tradition of the Graduation Day or Commencement Ceremony. It is true that the media show that, in the new Venetian ritual, there is almost complete adherence to the American model, however observing it carefully, it is possible to notice numerous structural elements that make it different. The traditional Italian graduation session: a) takes place within a closed space of the University, which usually takes the form of a lecture hall or a classroom; b) is a ceremony in which the individual graduating students discuss their own written work and they are proclaimed doctors with a final marks of which they become aware at that specific moment; c) the participants are: the graduating student, a commission of professors (including the thesis supervisor and commission chairperson) and the general public generally composed of relatives, friends and classmates invited for the occasion; d) is a ceremony that fits within what are called graduation sessions and usually a single committee can discuss from 6 to 15 theses in one day; e) on a temporal level, the session itself lasts between 20 minutes and 40 minutes (if the announcement takes place immediately after the 
discussion) but it is often preceded by a waiting phase and followed by some celebrations with the public invited for the ceremony; f) one of the symbolic devices of the graduate, just proclaimed, is the laurel wreath and, in many cases, the professors of the commission wear gowns. Instead, the American Graduation Day or Commencement Ceremony: a) usually takes place in a very spacious (often outdoor) area, which is part of the university campus; $b$ ) is a collective ceremony in which a large number of students attend and celebrate the graduation through a public event that consists of parades, speeches, awarding diplomas and a collective degree proclamation, in which the order often derives from the vote (of which students are already aware); c) the participants are the students, the rectors, the teaching staff, the guests of honor and the audience made up of relatives and friends (in some cases there is a ticket to pay); $d$ ) is a ceremony that takes place once or twice a year and in which the graduates of the class of that specific court participate (it is possible to participate in the event, having still some university tests to pass); e) on a temporal level, the graduation day lasts between 2 and a half hours and 5 hours and consists of several phases that are usually: "procession," "commencement speech," "valedictorian speech" and usually proclamation with diploma delivery; f) the students are dressed in gowns and caps with a tassel which is symbolically moved from left to right at the moment of passage of status. The new Venetian ritual certainly presents many similarities to the American graduation day, in particular the idea of a collective celebration that consists of a speech by an invited guest, the speech of the best students of the university and a proclamation that sets the traditional cap toss. However, the $\mathrm{Ca}$ 'Foscari version has its own specificities that make it unique and, in some cases, presents similarities with the traditional graduation session. For example, students do not wear gowns and the cap is placed on the head just after the delivery of the diploma.

\section{RESULTS}

Saint Mark's Square: the non-symbolism of a place

During the period that precedes the first celebration of the new graduation ritual of the Venetian university, the Rector of the University repeatedly refers to Saint Mark's Square as a privileged place ("memorable") on which to perform the ritual and there are actually many people in the audience (relatives and friends) who, while waiting for the ceremony, look around and take pictures of the Square. In fact, the spectacularity of the place should not be underestimated in an era - as Debray emphasizes - when ritual manifestations are negotiated within an interpretive arena dominated by mass media, oriented by a growing cult of image (Navarini, 1999). Apparently it could therefore represent the ideal place, however, the comparison with the other ritual variants brings out some ambivalent aspects. First of all, in the square, being public, outdoor and far from the university area, there are some subjects - for example, the tourists who visit the city and inhabitants with their commercial activities - that perform in that same place 
functions completely independent of the ritual. Moreover, the place is symbolic, but its symbolism is not tied to the object of the ritual as much as to the public imaginary of the city: thus, it is difficult to imagine a connection between the student experience of the classrooms of the palaces in Dorsoduro and Canareggio neighborhoods and the most famous square of the city. This last aspect seems to be highlighted - perhaps unknowingly - by the mayor Orsoni when, during the first graduation ceremony of 2011, he states: "This event, the Graduation day, not only had to be set here in the most important and representative square of Venice, but will have to remain in the future a symbolic event of transition from the life of students to that of citizens of Venice. The Graduation day in Saint Mark's Square is the embrace of the city to all of you, ready to embark on new and exciting paths" (unive.it).

\section{Graduation Day: the space of the ritual}

Regarding the context in which the ritual takes place, I observed a social organisation of space that is articulated according to precise conventions: he space in which the ritual takes place is public and represents the area with the highest tourist flow in the city. The Square is mainly divided into two "quadricentric" areas: an external area where people enjoy the place regardless of the ceremony (citizens, city users and tourists) and an internal area where all the elements that characterise the ritual are present. The interior area is further divided into five parts: the backstage which is almost entirely visible to people outside the area (in this area there are soldiers, civil guards and some security guards); the red stage where the event takes place; the first rows of chairs where the authorities and future graduates can sit; the subsequent files dedicated to those relatives and friends who have the possibility - through an official invitation - to access the area; and all interstitial areas where where it is possible to walk and where are people who manage the spaces and those who access it. Near the entrances, there are advertising banners of the sponsors of the event. There are four entry/exit areas, two for graduating students and two for the relatives and friends and it is not possible to enter jointly. Thus, the situation that is configured in the access areas is:

- at the guests entrance, the "privileged ones," who can be a maximum of three for each student, are separated from the other relatives and friends. Generally, considering that the event lasts for more than two hours, it is not always the closest relatives to enter: for example, the grandparents of the graduate come in instead of the parents. In addition, people with an official invitation receive a booklet in which, beyond the program of the event, there is a greeting and thanks from the Rector, the presentation of the guest of the ceremony and of the Caumans Association Ca 'Foscari, the names in alphabetical order of the 756 future doctors and the presentation of the University Master's degree courses.

- at the students entrance, each graduating student expects his / her turn to enter without interacting with the other ones, but by calling the relatives and friends who are in other places in the square. 
The Venetian ritual: four actors

Taking into account the Goffmanian perspective, we can say that, instead of three, there are four participants in the Venetian ritual: the future graduates (first actor), the institutional authorities who confer the title and give meaning to the celebration (second actor), the audience composed of family and friends (third actor) and all the people who, for different reasons, pass through the square and become involuntary public of the event. The presence of the fourth actor is particularly significant: the tourists are divided between those who, after taking some pictures of the square and its monuments, disappear among the narrow streets of the city and those who, intrigued by the event, decide to assist leaning on the barriers as all "guests without privilege". Sometimes a Venetian citizen crosses the square and, having met some friends who have been invited to the event, greets them and congratulates for the title obtained by the young relative. Lastly, those who have commercial activities in the square, take advantage of the event for economic purposes. The public undergoes control in so far as it is dragged to react "as befits" a show (like the final applause). Instead, the students are spectators in the first phase of the graduation day and active participants in the second part, that of the proclamation. Unlike the traditional graduation session, in this case there is a collective dimension that takes away the connotations of the graduating student (which are not even divided by department) while, compared to the American model, it is immediately evident that the Venetian collective dimension is not a sharing situation. Indeed, few students know the other student who is sitting next to them as Bachelors come to have 150 students for each court, most of whom live off campus. Regarding the authorities present at the ceremony, compared to the traditional ritual the differences are huge and concern the composition of the commission as well as the interaction between the graduating student and the professors present at the event: here the interaction is limited to a handshake with the rector and the function of the professors, seated in a semicircle in the rear part of the stage, is simply to be present. And what are the customs - which are also the symbols - that characterise this new ritual? It is a cross between the traditional Italian and American variant: while it is true that students do not have gowns, the professors - as it is also in America - have gowns that transmit to the audience the credentials and academic achievements of the professors (Magolda, 2003); it is true that the students have caps, however, they put them on their heads only at the close of the delivery of the diploma and there is no American ritual of moving the tassle from left to right.

\section{The Venetian ritual: the limelight}

Three announcements, one after the other, mark the beginning (the first time boundary) of the ceremony: in the first announcement, the speaker informs that the ceremony is about to start and reminds the graduates to sit in the chairs in the first rows; then follows a procession that accompanies the second announcement in which people are invited to turn off their phones 
and remember to share the event on social networks (with the hashtag "laureacafoscari"). Lastly, the ceremony begins with the words: "the graduation ceremony for the extraordinary session 2015/2016 begins." These first three communications are already interesting: first, unlike the traditional graduation session, the distance that students must keep from their families is repeated several times; second, beyond the contradiction of inviting phones to be turned off and at the same time asking to use them to share the event, the choice to share the event on social networks can bring back to a liminoid dimension of theatricality. Lastly, in the final-initial communication, by referring only to the delivery of diplomas, the announcer degrades (perhaps unconsciously) the entire structure of the graduation event surrounding the proclamation. The first act includes the speech by the Rector of the Ca 'Foscari University (on the American model) and the speech by the Vice-President of the Veneto Regional Council, aiming to emphasie the link between the City and the University. Later the best Italian student and the best foreign student (who that year was a Moldovan girl) are called to speak on stage, respectively. This practice is clearly deduced from the US model "Valedictory," however the idea of wanting to distinguish the best Italian student from the foreign one is a local peculiarity that while, on the one hand, may seem as a discriminatory act, on the other hand, could make it coincide with the will, on the part of the university, to underline the international vocation that the University pursues. In any case, it is important to consider that the choice to adopt this practice has contradictions and, in fact, as Tony Waters (2003), professor of sociology at the University of California, emphasizes, the choice to reward those who have succeeded in an excellent way to respond to the requests of professors without ever stumbling risks to take away space for those who, having faced and overcome their intellectual limits in the university (the so-called 'Humbilitorians'), could represent the true protagonists of the university experience: "[...] Humbilitorians, students receiving a low grades now and then recognise early that perfection in all things is not necessarily an essential goal for its own sake, or even possible" (Waters, 2003). Even the way to select the candidate for the best student in the session may seem contradictory. At the Ca 'Foscari University the criteria chosen to compare the performance of the students are the calculation of the average score of the single student and the comparison of the same average score with that of their class. While on the one hand, it seems a valid method, looking carefully, it can be noted that the faculties where people are enrolled by vocation rather than for reasons of job opportunities are disadvantaged: if the vocation among the students who choose these faculties are strong (and consequently the results are often high) the gap with people with lower average score is necessarily wider. In the American model, the second act includes the opening speech of a guest invited specifically for the ceremony. In the graduation session 2017 it was the former student of the Ca 'Foscari University and journalist who was awarded the Pulitzer Prize 2017, Alessia Cerantola. The guests deliver a speech that aims to be an inspiration for the young graduationg students. Referring to the writings of Kuh (1988), who identified some important objectives that are sought to 
be pursued in the ritual events of university campuses, Magolda (2003) points out that four objectives are relevant in the American graduation day ritual: a) to recognise the results achieved, b) to encourage students to reflect on the meaning of their university experience, c) to cultivate faithful graduates, d) to facilitate the transition to life after university. Firstly, the recognition of the results achieved is highlighted by both the Rector and the Italian valedictorian student: if the first states "you are certainly better people than when you arrived: [...] because you grew up intellectually and learned to read reality with a critical spirit," the second adds "I think back to the difficulties but also to the commitment, satisfaction, determination and curiosity that have led us to be here today." Secondly, the reflection on the meaning of the university experience is highlighted a bit by all the figures that follow each other onto the stage. Furthermore, from the same point of view, the vaguely nostalgic speech of the best Italian student is significant: "I think I speak for everyone to remember when we set out to study from the first day of class and when we regretted not having done so, when we studied until late at night before the examination and sometimes even the morning itself." Thirdly, the willingness to cultivate faithful graduates is particularly evident in both the Rector's speech when he specified that the students, wherever they go, will remain children of the Venetian university and when - especially in the booklet - the students are invited to continue studies with the master's degree, if possible, drawing on the wide range of master's degrees at the $\mathrm{Ca}$ 'Foscari University (also stating that the Master is a deeper experience, in which the relationship with the professors will also be different). Lastly, the reference to life after graduation is almost in all interventions: the rector who says "this is the end of a path but also the beginning of another that continues with new experiences," the suggestions for the future of guest of honour: "collaborating, traveling, drawing inspiration from the past with detachment and without being anachronistic, listening but not allowing others to decide for us," the best foreign student who says "the degree that is a key that will allow us to discover new worlds. A new chapter of our life full of hopes and dreams will begin tomorrow" and the commemorative reference to Valeria Solesin (a Venetian social researcher who was studying in Paris and died in the Bataclan terrorist attack) by the Vice-President of the Veneto Regional Council: "'Our challenge must always be to change things, never stop, Valeria would never allow me'. These were the words pronounced about a year and a half ago in this square by Dario Solesin, brother of Valeria, a young researcher who today we want to remember with you. I would like this feeling of justice, openness, never to stop, to change things is the message that you then take from this event to the future." Then, two aspects that recur in the words of the protagonists are: the centrality of the students in reference to the event ("the real protagonists are you"), the centrality of the city, and the need to elaborate a definition of the situation that connects the past to the present. For example, if the Rector states "success is never definitive, failure is never total, but what really matters is the courage and enthusiasm to continue," the best Italian student says "no amount of remorse can change the past, no amount of anxiety can change the future. We can change." 


\section{The proclamation as a transition}

Without a doubt, on the analytical level, the most significant moment of the ceremony is the delivery of the graduation scrolls and the following proclamation: two rows of students are created on the outer sides of the stage, the students put the caps on their heads and, one by one, are invited to collect the graduation parchment. The graduating students of the session are 756: an endless list of students who follow each other on stage at a steady pace for more than an hour. Their names, enunciated at a perfectly rhythmic taunt, are listed without any kind of connotation as in the event booklet. It seems to fit perfectly into the ritual style of the liminal phase in which the neophytes are leveled to a uniform condition in order to remodel them later (Turner, 2001). The time on stage of the graduating students lasts just five seconds in which, as if it were a dance (this is a significant step made of specific social conventions in all the variants of the genre, just think of the final scene of movie Patch Adams, in which the protagonist takes the role of the free rider), a single student approaches the Rector, with his right hand he/she shakes the hand of the rector, with his/her left hand he/she takes the parchment and at the end he/she approaches the Rector with whom a photograph is taken. Meanwhile, groups in the public - both inside and outside the barriers - "are shouting" at the passage of their friend or family about to graduate. The interesting aspect of this moment is that I begin to notice two aspects concerning the so-called concept of social distance (Hall, 1982). Firstly, many people in the audience complain that they cannot enjoy the moment because they are too far away and, in fact, compared to the traditional graduation session, there is a public distance rather than a social distance. Secondly, as regards the handshake between the person who embodies the authority and the student compared to the traditional graduation session, there are apparently no particular differences in the distance between the two Protagonists. However, the meaning changes totally and this can be seen from the fact that the protagonists of the new ritual shake hands without maintaining eye contact. This, I could hypothesise, derives from the fact that while in the traditional form of ceremony there is a relationship of reciprocal knowledge, even minimal, between the two subjects, at least for the thesis supervisor, in the new ritual they are basically two people who have never had contact before. Furthermore, it should be noted that, compared to the traditional graduation session, there is a split: if the traditional sequence included, in order, discussion of the thesis, proclamation and finally handshake to each individual member of the commission (in some cases also the parchment delivery), in the new ritual there are two moments of proclamation: in fact, in fact, due to the collective formulation of the phrase "with the powers conferred me from the state I declare you doctors of the Ca 'Foscari University of Venice," the public interprets the handshake as the first moment of proclamation and the aforementioned words as the second moment of proclamation. This aspect is particularly evident in the fact that the various groups of relatives and friends, very soon, start and behave like some supporters during the delivery of the parchments. 
After the proclamation, if, with respect to the American model, students are not expected to move the tassle from left to right, the cap is expected to be tossed and in this case the moment is accompanied by the song "People have the power" by Patti Smith. The effect of music accompanied by black caps in the air is particularly significant on the emotional level; many students and families are moved and, as Mosse says, this can be derived from the seduction fed by spectacular techniques and theatricality (Navarini, 1999). However, unlike American ceremonies, during which it often happens that the whole court participates and celebrates the same graduation day together, the newly graduated students as soon as they toss their caps - not knowing each other - do not exchange greetings or hugs with the other students but they are immediately committed to reaching the people who are waiting for them. Lastly, I want to highlight the ambiguity of a collective ceremony, in which there was no way or time to focus on the ritual a single student is involved in the commentaries of the parents of recent graduates highlight more the spectacle of the event and of the context in which it was held than the significance of the rite for the protagonists.

In which phase of the rites of passage does the event take place?

According to the analysis of the American variant, there are three different ways in which the graduation session is interpreted as a rite of passage (as Van Gennep intends). Magolda (2003) argues that during the separation, the individual or group is liberated in a symbolic or physical way from their present situation of students attending the university. The transition is, instead, a moment of flow between the present and the future. Incorporation occurs when a new status is acquired: for example, when you get a job or you are enrolled in the second cycle study path.

- Others (newworldencyclopedia.org) argue that the three phases are fully incorporated into the graduation ceremony: the first phase is accomplished when the participants are separated from their social environment by making them wear distinctive clothes; the second phase is the period during which one is "betwixt and between", i.e. when the ceremony is in progress, the participants are no longer students but they are not graduates yet, the third phase corresponds to the handshake after the delivery of the parchment, which establishes the public recognition of the new social status.

- In some cases the liminal phase is extended from the moment in which the last didactic activity was completed to the receipt of the parchment. This is because it is the moment when the student is relieved of the tasks but has not yet passed to a status different from the one he or she had before. From the ritual that I analysed emerged aspects of ambiguity of definition of the situation as a rite of passage. It is difficult to match the incorporation phase with the proclamation because the people who follow each other on the stage use the words graduating students and graduates as synonyms and the same audience perceives, as already said, a double 
proclamation between the delivery of the parchment and the conferment of the title (through the declaration). Personally I interpret the old graduation ritual in the following way: the separation phase coincides with the moment of discussion of the final paper because it is the first moment in which students exhibit their creative work which is - at least partially - the "mirror" of the preparation acquired in the three-year period; the liminal phase is the "no man's land"; while waiting to know the outcome and the incorporation is the proclamation phase. On the basis of the ethnographic study, I interpret the new graduation ritual in the following way: the separation phase corresponds to the delivery of the final paper to the thesis supervisor as the last didactic activity of the path; the limen is a phase with weak borders that goes from the moment when the final result is obtained up to the ceremony; the incorporation corresponds to both the delivery of the parchment and the conferment of the title. However, it is important to underline that, given the difficult current conditions of obtaining a job (according to their expectations) after graduation, it is not uncommon for the student to perceive the liminal phase even after obtaining the degree. Regarding Turner's distinction between the liminal and liminoid, the new ritual can be defined as liminal due to its cyclical nature and the passive role that the students assume (unlike the old graduation session) can be considered as liminoid because it does not provides evidence of "courage," and occurs in a different and separate place of the context of the cultural object to which it refers.

\section{CONCLUSION}

The new model of celebration differs so much from the traditional one that it is pertinent to wonder if there are elements of ambiguity and dissonance. First of all, there is a lack of consistency between the new degree model and the new graduation ceremony model. In fact, the aim of the Bologna process was not to devalue the first cycle degree (which should, at the same time, professionalise and provide the basis for the Master) but, at the time when the student who does not continue his or her studies after Bachelor is deprived, for the first time, of the possibility of choosing whether or not to discuss his or her final paper, the student begins to wonder what the significance of the Bachelor is compared to the past. And the declaration of the rector, "[f]or half of the students there had not been discussion for several years, and for several years they have appreciated the change that speeds up the course of study allowing them to then enroll in the master's degrees at the right time," questions this aspect. Furthermore, as it emerges from the analysis of the rector's statements (when he underlines that the value of the Bachelor's degree is more related to the prestige of the institution than to the modality of achievement), the university institutions must keep the prestige discourse in the foreground. In fact, nowadays universities have to compete in a scenario made up of international rankings that, although 
questioned by many parties, have a real impact in terms of obtaining funding. The rector's statement on the inspiration given by the graduation day of the Sorbonne University ("certainly not Anglophile") is interesting and contradictory: one might ask whether it is sufficient to replace the French model with the English one to reply to the criticisms and if it is not necessary to highlight a model of celebration renewed but consistent with the meanings proposed by our current university system. And that's why I decided to carry out an ethnographic research that allows me to see if the new model of celebration is consistent with the university system that can experiment on students in Italy (especially, in Venice). In this regard, the choice to develop a public ceremony, both in terms of space and structure, is the main innovation and it is, for this reason, the root and frame of the most decisive effects. On the one hand, the liminal theatricality of the event satisfies the demands of collective catharsis of the rite, and is also perfect for the university's marketing in its connection with the city. On the other hand, there is some ambivalences. Firsty, as already mentioned, the symbolism of Saint Mark's Square is linked to the social and tourist imagery of the city rather than to the university experience that the students have; thus, this space is also 'inhabited' by subjects unrelated to the event. This means also that students cannot choose the degree of confidentiality in which to perform the rite of passage. Secondly, oscillating between the sacredness of the liminal rite and the spectacularity of the liminoid as contradictory, contemporary to the request to share the event on social media, people are invited to turn off their mobile phones. Thirdly, the rhetoric of the speeches, which follows the US ceremony structure, could not be very effective: it is based on a model of student's university experience very different from the Italian one, in which students mostly do not live in the collective and exclusive dimension of campus life. The speeches that provide for a link between the university experience and the city try to make sense of this rhetoric, but it is also true that it does not take into account the fact that student daily commuting is a fact that involves more than large number of students (they often don't live the city outside the university classrooms). Lastly, as regards the tossing of the caps, for students it seems to be a significant moment, on emotional level, in their collective dimension but less from the point of view of sharing. Since the future graduates are distributed in space in alphabetical order, without distinction of department or court of belonging, in most cases students don't know people who are sitting next to them. Thus, the toss of a cap becomes a solitary moment followed by the swift search for classmates, friends and relatives who are waiting for them to celebrate. Furthermore, it pays too little attention to the original meanings of the model of celebration from which it draws: at the level of symbolic devices, while it is true that students wear the cap, they don't move the tassle from left to right. This means that one proceeds more by imitation than by sharing the meanings. There is not even a reflection on the criticality of the model from which it draws (valedictory model) and, therefore, on the choice of how to adapt it without 'stumbling' in the same criticality: it is a case of the choice to have the best student speak in front of the public. Choice 
often criticised because it penalises those who have faced their difficulties (the 'Humbilitorians') and graduated exceeding their intellectual limits. In conclusion, I would like to say that rituals are sociocultural forms of production of very important meanings, whose modification could be more satisfactory if involved a large number of subjects belonging to different groups. Furthermore, choosing a new model of ritual by referring with little attention to other models and without a deeper reflection on Italian educational models (in the context of higher education) means not caring for them and this is in the opposite direction of the objectives of becoming competitive in terms of international recognition from which the same choice of innovation started.

\section{REFERENCES}

[1] La tesi di laurea (triennale) oggi non si discute più [The final paper (Bachelor) is no longer discussed] (2012). Retrieved from https://www.controcampus.it/2012/06/la-tesi-di-laurea-triennale-oggi-non-si-discute-piu/ [2017]

[2] Ballarino, Gabriele, e Hans M. A. Schadee (2008). La disuguaglianza delle opportunità educative in Italia, 1930-1980: tendenze e cause [The inequality of educational opportunities in Italy, 19301980: trends and causes]. Polis, n. 3/2008

[3] Barone, C. (2012). Contro l'espansione dell'istruzione (e per la sua ridistribuzione) : il caso della riforma universitaria del 3+2 [Against the expansion of education (and its redistribution): the case of the university reform of $3+2]$. Scuola Democratica $4, n .1$.

[4] Becker, H. S. (1963) Outsiders. Simon and Schuster.

[5] Bernabei, V. (2011) . E sulla tesi adesso non si discute più [And the thesis is now no longer discussed]. Retrieved from http://temi.repubblica.it/guide-universita-2011/2011/07/05/esulla-tesi-adesso-non-si-discute-piu/ [2017]

[6] Bettini, A. (2008). Università, cerimonie addio e la laurea arriva in un minuto [University, ceremonies, goodbye and graduation comes in a minute]. Retrieved from http://www.repubblica. it/2007/09/sezioni/scuola_e_universita/servizi/lauree-facili/lauree-veloci/lauree-veloci. html [2017]

[7] Burnett, J. (1969). Ceremony, Rites, and Economy in the Student System of an American High School. Human Organization 28, n. 1.

[8] Ferro, C. (2011). Lauree all'americana a Ca' Foscari. Discussioni abolite per le triennali [American-style graduation at Ca 'Foscari. Discussions abolished for the Bachelor's degree]. Retrieved from http://www.universita.it/lauree-allamericana-a-ca-foscari-discussioni-aboliteper-le-triennali/ [2017]

[9] Ferro, C. (2011). Lancio del tocco per 500 in piazza San Marco. Con protesta [Launch of the caps for 500 student in Saint Mark's Square. With protest]. Retrieved from http:/ / www.universita.it/ laurea-piazza-san-marco-severgnini-protesta/ [2017]

[10] Geertz, C. (1973). The Interpretation of Cultures: Selected Essays. Basic Books.

[11] Griswold, W. (1987). A Methodological Framework for the Sociology of Culture». Sociological Methodology 17: 1.

[12] Hall, E. T. (1982). The Hidden Dimension. Anchor Books.

[13] Kuh, G. D., Whitt E. J. (1988). The Invisible Tapestry: Culture in American Colleges and Universities. Wiley.

[14] Lago, A. Dal, De Biasi, R. (2014). Un certo sguardo: Introduzione all'etnografia sociale [A certain look: Introduction to social ethnography]. Gius.Laterza \& Figli Spa.

[15] Magolda, P. M. (2003). Saying Good-Bye: An Anthropological Examination of a Commencement Ritual. Journal of College Student Development 44, n. 6.

[16] Moscati, R. (2010). Le trasformazioni dell'università italiana [The transformations of the Italian university]. Scuola Democratica 1, n. 1. 
[17] Navarini, G. (1999). Il congresso di Forza Italia: descrizione di una performance rituale [The Congress of Forza Italia: description of a ritual performance]. Rassegna Italiana di Sociologia, $\mathrm{n}$. $4 / 1999$.

[18] Navarini, G. (2003) L'ordine che scorre: introduzione allo studio dei rituali [The flowing order: introduction to the study of rituals]. Carocci.

[19] Quantz, R. A. (1999). School Ritual as Performance: A Reconstruction of Durkheim's and Turner's Uses of Ritual. Educational Theory 49, n. 4. 19

[20] Roesel, Lorenzo (2016). Niente discussione alla laurea triennale? Lo "sconto" che gli studenti non vogliono [No discussion at the three-year degree? The "discount" that students do not want]. Retrieved from http://www.ilsussidiario.net/News/Educazione/2016/1/19/ UNIVERSITA-Niente-discussione-alla-laurea-triennale-Lo-sconto-che-gli-studenti-nonvogliono/671429/ [2017]

[21] Tota, A. L. (2003). La comunicazione pubblica del passato. Uno studio etnografico sulla commemorazione della strage di Bologna [Public communication of the past. An ethnographic study on the commemoration of the Bologna massacre]. Rassegna Italiana di Sociologia, n. 1/2003.

[22] Turner, V. W. (1974). The Ritual Process: Structure and Anti-Structure. Penguin Books Limited.

[23] Van Gennep, A. (2013). The Rites of Passage. Routledge.

[24] Wagner-Pacifici, R., Schwartz, B. (1991). The Vietnam Veterans Memorial: Commemorating a Difficult Past. American Journal of Sociology 97, n. 2.

[25] Waters, T. (2003). The problem with valedictorians. Retrieved from https://www.newsreview.com/chico/problem-with-valedictorians/content?oid=26874 [2017] 